\title{
Salivary Gland Pleomorphic Adenoma
}

National Cancer Institute

\section{Source}

National Cancer Institute. Salivary Gland Pleomorphic Adenoma. NCI Thesaurus. Code C40409.

A benign, slow-growing tumor composed of cells that demonstrate both epithelial and mesenchymal differentiation. It is the most common neoplasm of salivary gland origin, and mostly occurs in the parotid gland. The average age of patients has been reported to be 43 years; women are more often affected than men. The malignant change rate has been estimated to be $6 \%$. The malignant counterpart is carcinoma ex pleomorphic adenoma. 